\title{
GLRB allelic variation associated with agoraphobic cognitions, increased startle response and fear network activation: A potential neurogenetic pathway to panic disorder
}

Jürgen Deckert ${ }^{1 * \#}$, Heike Weber ${ }^{1,2 \#}$, Carmen Villmann ${ }^{3}$, Tina B. Lonsdorf ${ }^{4}$, Jan Richter ${ }^{5}$, Marta Andreatta $^{6}$, Alejandro Arias-Vasquez ${ }^{7}$, Leif Hommers ${ }^{1,8}$, Lindsey Kent ${ }^{9}$, Christoph Schartner ${ }^{1}$, Sven Cichon ${ }^{10,11,12,13}$, Christiane Wolf ${ }^{1}$, Natascha Schaefer ${ }^{3}$, Cora R. von Collenberg ${ }^{3}$, Britta Wachter $^{3}$, Robert Blum ${ }^{3}$, Dirk Schümann ${ }^{4}$, Robert Scharfenort ${ }^{4}$, Johannes Schumacher ${ }^{10,11}$, Andreas J. Forstner ${ }^{10,11}$, Christian Baumann ${ }^{1}$, Miriam A. Schiele ${ }^{1}$, Swantje Notzon ${ }^{14}$, Peter Zwanzger $^{14,15}$, Joost GE Janzing ${ }^{16}$, Tessel Galesloot ${ }^{17}$, Lambertus A. Kiemeney ${ }^{17}$, Agnes Gajewska ${ }^{1}$, Evelyn Glotzbach-Schoon ${ }^{6}$, Andreas Mühlberger ${ }^{18}$, Georg Alpers ${ }^{19}$, Thomas Fydrich $^{20}$, Lydia Fehm ${ }^{20}$, Alexander L. Gerlach ${ }^{21}$, Tilo Kircher ${ }^{22}$, Thomas Lang ${ }^{23,24}$, Andreas Ströhle ${ }^{25}$, Volker Arolt ${ }^{14}$, Hans-Ulrich Wittchen ${ }^{23}$, Raffael Kalisch ${ }^{26}$, Christian Büchel ${ }^{4}$, Alfons Hamm $^{5}$, Markus M. Nöthen ${ }^{10,11}$, Marcel Romanos ${ }^{27}$, Katharina Domschke ${ }^{1}$, Pauli Pauli ${ }^{6 \#,}$ Andreas Reif ${ }^{2 \#}$

1) Department of Psychiatry, Psychosomatics and Psychotherapy, Center of Mental Health, University Hospital of Würzburg, Würzburg, Germany

2) Department of Psychiatry, Psychosomatic Medicine and Psychotherapy, University Hospital of Frankfurt, Frankfurt, Germany

3) Institute for Clinical Neurobiology, University Hospital of Würzburg, Würzburg, Germany

4) Department of Systems Neuroscience, University Medical Center Hamburg-Eppendorf, Hamburg, Germany

5) Institute of Psychology, University of Greifswald, Greifswald, Germany

6) Institute of Psychology, and Center of Mental Health, University of Würzburg, Würzburg, Germany

7) Donders Institute for Brain Cognition and Behavior, Departments of Psychiatry, Human Genetics and Cognitive Neuroscience, Radboud University medical center, Nijmegen, The Netherlands

8) Interdisciplinary Center for Clinical Research, University Hospital of Würzburg, Würzburg, Germany

9) School of Medicine, University of St. Andrews, Scotland

10) Department of Genomics, Life \& Brain Center, University of Bonn, Bonn, Germany

11) Institute of Human Genetics, University of Bonn School of Medicine \& University Hospital Bonn, Bonn, Germany

12) Division of Medical Genetics, University Hospital Basel, and Department of Biomedicine, University of Basel, Switzerland

13) Institute of Neuroscience and Medicine (INM-1), Research Center Juelich, Juelich, Germany

14) Department of Psychiatry and Psychotherapy, University Hospital of Münster, Münster, Germany 
15) Department of Psychiatry and Psychotherapy, District Hospital Gabersee, Wasserburg, Germany

16) Department of Psychiatry Radboud University medical center, Nijmegen, The Netherlands

17) Radboud Institute for Health Sciences, Radboud University medical center, Nijmwegen, The Netherlands

18) Institute of Psychology, University of Regensburg, Germany

19) Department of Psychology, School of Social Sciences, University of Mannheim, Mannheim, Germany

20) Institute of Psychology, Humboldt University, Berlin, Germany

21) Institute of Clinical Psychology and Psychotherapy, University of Cologne, Cologne, Germany

22) Department of Psychiatry and Psychotherapy, University Hospital of Marburg, Marburg, Germany

23) Institute of Clinical Psychology and Psychotherapy, TU Dresden, Dresden, Germany

24) Christoph-Dornier-Foundation for Clinical Psychology, Bremen, Germany and Institute of Psychology, University of Hamburg, Germany

25) Department of Psychiatry and Psychotherapy, Campus Charité Mitte, Charité University Medicine, Berlin, Germany

26) Neuroimaging Center (NIC) und Deutsches Resilienz-Zentrum (DRZ), Johannes Gutenberg University Medical Center, Mainz, Germany

27) Department of Child and Adolescent Psychiatry, Psychosomatics and Psychotherapy, Center of Mental Health, University Hospital of Würzburg, Würzburg.

\#Jürgen Deckert and Heike Weber share first authorship, Paul Pauli and Andreas Reif share last authorship.

*Correspondence and material requests should be addressed to Jürgen Deckert, Department of Psychiatry, Psychosomatics and Psychotherapy, University of Würzburg, Füchsleinstr. 15, D-97080 Würzburg, Germany; Tel.: +49 (0)931 201 77000; Fax: +49 (0)931 201 77020; eMail: Deckert J@ukw.de

Running title: GLRB allelic variation and panic disorder

Number of words in the abstract/ main text/ online methods: 242/3484/ 1530

Total number of figures / tables / supplements: 4/ 1/ 9

Keywords: Agoraphobia, GWAS, GLRB, Startle, Fear Network, Spastic Mouse, Panic Disorder 


\section{Abstract}

The molecular genetics of panic disorder (PD) with and without agoraphobia (AG) are still largely unknown and progress is hampered by small sample sizes. We therefore performed a genome-wide association study with a dimensional, PD/AG - related anxiety phenotype based on the Agoraphobia Cognition Questionnaire (ACQ) in a sample of 1,370 healthy German volunteers of the CRC TRR58 MEGA study wave 1. A genome-wide significant association was found between ACQ and single non-coding nucleotide variants of the GLRB gene ( $r$ 78726293, $\left.p=3.3 \times 10^{-8} ; \mathrm{rs} 191260602, p=3.9 \times 10^{-8}\right)$. We followed up on this finding in a larger dimensional ACQ sample $(\mathrm{N}=2,547)$ and in independent samples with a dichotomous AG phenotype based on the Symptoms Checklist (SCL-90; N=3,845) and a casecontrol sample with the categorical phenotype PD/AG $\left(\mathrm{N}_{\text {combined }}=1,012\right)$ obtaining highly significant $\mathrm{p}$-values also for GLRB single nucleotide variants $\operatorname{rs} 17035816\left(p=3.8 \times 10^{-4}\right)$ and rs7688285 $\left(p=7.6 \times 10^{-5}\right)$. GLRB gene expression was found to be modulated by rs7688285 in brain tissue as well as cell culture. Analyses of intermediate PD/AG phenotypes demonstrated increased startle reflex and increased fear network as well as general sensory activation by GLRB risk gene variants rs78726293, rs191260602, rs17035816 and rs7688285. Partial Glrb knockout-mice demonstrated an agoraphobic phenotype. In conjunction with the clinical observation that rare coding GLRB gene mutations are associated with the neurological disorder hyperekplexia characterized by a generalized startle reaction and agoraphobic behavior, our data provide evidence that non-coding, though functional GLRB gene polymorphisms may predispose to PD by increasing startle response and agoraphobic cognitions. 


\section{Introduction}

Panic disorder (PD) with a life-time prevalence of 2-3 percent, causing a huge burden of disease ${ }^{1}$, is characterized by sudden panic attacks, anticipatory anxiety of the next panic attack and frequently accompanied by agoraphobia (AG) ${ }^{2}$. AG is a clinical condition characterized by abnormal open space behavior ${ }^{3}$ and, importantly, distorted cognitive processes ${ }^{4}$ thus reflecting a dimensional phenotype which can be assessed with the Agoraphobic Cognitions Questionnaire (ACQ) ${ }^{5}$. Family studies reveal familial aggregation in $P D$ and $A G{ }^{6,7}$ and twin studies estimated heritabilities of about $38 \%$ and $48 \%$, with a genetic correlation of 0.83 between both disorders ${ }^{8}$.

Linkage and candidate gene association studies of PD/AG were mostly negative or inconsistent ${ }^{9-12}$ due to phenotypic diversity, genetic heterogeneity and underpowered sample sizes. Of the candidate genes, only the catechol-O-methyltransferase (COMT) ${ }^{13-15}$ gene, the neuropeptide $S$ receptor gene (NPSR1) ${ }^{16}$ and the monoamine oxidase $A$ (MAOA) gene ${ }^{17-19}$ have been implicated in susceptibility to PD by several independent studies and meta-analyses within the European population ${ }^{11,12,20,21 .}$

Two genome-wide association studies (GWAS) on PD/AG ${ }^{22-25}$ have been published. In contrast to the more advanced GWAS e.g. in schizophrenia ${ }^{26}$, GWAS in PD are characterized by small sample sizes (hundreds versus thousands). However, the TMEM132D gene identified in a GWAS was confirmed in the European population in an independent metaanalysis ${ }^{11}$. An alternative approach utilized were GWAS studies on dimensional traits (neuroticism and phobic anxiety) ${ }^{27-29}$, which supported a locus on chromosome 1 , but so far showed inconclusive results with regard to individual genes. Recently, an approach studying anxiety disorders combined and quantitative phenotypic scores was applied providing genome-wide evidence for a non-coding RNA locus on chromosome 3q12.3 and the CAMKMT (calmodulin-lysine $\mathrm{N}$-methyltransferase) gene on chromosome $2 \mathrm{p} 21^{30,31}$.

Assuming a dimension from agoraphobic cognitions to full PD/AG, we (1) conducted a GWAS on a dimensional anxiety phenotype (ACQ) in a sample of 1,370 healthy German volunteers to generate hypotheses for further investigations. We then (2) evaluated the GLRB locus in a larger dimensional ACQ sample, comprising 2,547 healthy volunteers. Next, we validated our findings (3) in a Dutch control sample $(\mathrm{N}=3,845)$ with a dichotomous 
measure of AG symptoms [SCL-90] and (4) assessed the relevance of the association for the categorical phenotype PD/AG by analyzing 506 case-control pairs. To probe molecular consequences of GLRB genetic variation, we (5) measured mRNA expression in vitro and post mortem. As single nucleotide mutations in GLRB underlie hyperekplexia 2 (OMIN \#614619), characterized by exaggerated startle response, we examined the effect of the identified GLRB risk polymorphisms on startle habituation (6), potentiation (7), and generalization (8). This was complemented by (9) fMRI analysis of fear network and general sensory activation. Finally (10), we performed an analysis of agoraphobic behavior in mice with a partial Glrb knock-out. 


\section{Materials and Methods}

\section{GLRB locus, agoraphobic cognitions and PD/AG}

Samples

To identify loci associated with agoraphobic traits as defined by the ACQ ${ }^{5}$ (German version ${ }^{32}$ ), we examined 1,370 healthy German volunteers by conducting a GWAS and then evaluated the genome-wide significant locus in a larger sample comprising 2,547 German healthy controls (MEGA study waves 1 and $2^{33,34}$ ). We validated the locus in 3,845 independent Dutch participants of the Nijmegen Biomedical Study (NBS ${ }^{35}$ ) for a dichotomous SCL-90 ${ }^{36,37}$ (Dutch version ${ }^{38}$ ) based agoraphobic cognitions phenotype and at

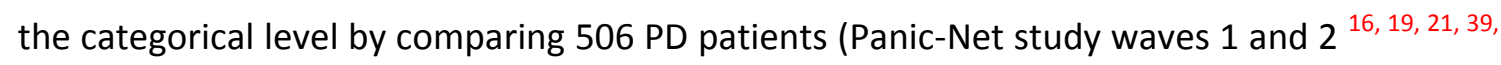
${ }^{40}$ ) with 506 matched controls from MEGA study waves 1 and 2. In all but the NBS studies, PD/AG patients and probands with severe psychiatric, neurological, or somatic disorders as well as drug and alcohol abuse were excluded. Only individuals with written informed consent were enrolled, which complied with the Declaration of Helsinki and was approved by the respective local Ethics Committee. For a demographic overview see supplementary table 1.

\section{Genotyping}

Participants of the MEGA wave 1 sample were genotyped on Illumina's HumanHap550v3 BeadChips using the Infinium II assay (Illumina, San Diego, CA, USA) at the Department of Genomics, Life \& Brain Center, University of Bonn, Germany. Quality control procedures were performed as described previously ${ }^{41}$ with slightly modified exclusion criteria (SNPs and subjects with call rates (CR) $\leq 99 \%$; minor allele frequency (MAF) $\leq 1 \%$; failing Hardy-Weinberg equilibrium (HWE) $\left(p<10^{-5}\right)$; principal component analysis $(P C A)>$ 4 fold SD of the first three principal components. To increase genomic coverage, imputation was conducted using MACH v1.0.18.c/ MINIMACH v2013-07-17 ${ }^{42,43}$ and the 1000 Genomes reference data set ${ }^{44}$. Post-imputation $Q C$ includes: SNPs and subjects $C R \geq 95 \%, M A F \geq 1 \%$, failing HWE $\left(p \geq 10^{-5}\right)$, imputation quality score $(I Q S)<0.3$, population stratification, gender and unreported relatedness check. The GWAS was free from genomic inflation in QQ-plots $(\lambda=1.000933)$ as shown in supplementary figure 1 . 
NBS was genotyped using the Illumina Human Omniexpress-12 and -24 chip. The preimputation QC steps applied to the NBS cohort include: SNP MAF $>1 \%, \mathrm{HWE}>10^{-4}$, SNP yield and individual CR>95\%. Imputation was done using IMPUTE v2.3.0 following the BBMRI-NL pipeline (http://www.bbmriwiki.nl/wiki/Impute2Pipeline) using the 1000 genomes phase 1 v3 and GoNL reference panels combined. Post-imputation QC comprised a gender check, unreported relatedness between participants and population stratification.

For fine mapping we captured GLRB and its flanking regions $(+40 /-10 \mathrm{~kb}$ upstream/downstream) by 21 tagSNPs derived from dbSNP European data (http://manticore.niehs.nih.gov/snpinfo/snptag.htm). Genotyping was performed using the Sequenom MassArray system (Sequenom, San Diego, CA, USA; for Primer sequences see supplementary table 2) and for rs17035628 using a "KASP on demand" assay (LGC Genomics, Hertfordshire, UK) as recommended by the manufacturers. After QC, the final dataset included 20 (two GWAS SNPs + 18 tagSNPs) markers with a MAF $\geq 1 \%, \mathrm{CR} \geq 90 \%$ and $\mathrm{HWE}$ (controls only) $\mathrm{p} \geq 0.01 ;$ rs17035590, rs17035814 and rs17035628 had to be excluded.

For details on statistical and power analysis see supplementary methods.

\section{Functional assessment: Bioinformatic, post mortem and cell system expression analyses}

To detect functional variation on expression of GLRB and neighbor genes, we analyzed our strongly associated variants, using the GTEx eQTL database (http://www.gtexportal.org/home).

For expression analysis of the promotor SNP rs7688285, post-mortem brain samples of 76 individuals (mean age $48.6 \pm 12.8$ ) were obtained from the Medical Research Council (MRC) Sudden Death Brain and Tissue Bank, Edinburgh. Detailed information on the sample and mRNA quantification are described elsewhere ${ }^{45}$. Allele-specific changes of rs7688285 on mRNA expression were calculated by linear regression with genotype and sample RIN as independent and expression values as dependent variable according to a dominant model.

For expression analysis in a heterologous cell system, 20 bp flanking rs7688285 upand downstream were subcloned into pGL4.23 vector for both alleles, allowing expression of firefly luciferase under the control of a minimal promotor. For details see supplementary methods. 


\section{Functional assessment: Startle Reflex}

\section{Samples}

Participants of MEGA and PanicNet waves 1 , who had taken part in various assessments of defensive behavior $33,46,47$, were studied regarding the effect of GLRB variation on startle reflex modulation. Individuals carrying at least one GLRB risk allele (i.e., those highly significantly associated with either ACQ or PD, namely: rs78726293 (A allele), rs191260602 (G allele), rs17035816 (G allele) or rs7688285 (A allele) were classified as "risk allele carriers". Accordingly, of 101 healthy volunteers who participated in an emotionpotentiated startle paradigm 24, of 76 healthy volunteers who participated in a context conditioning paradigm 23, and of 115 PD/AG patients who participated in a behavioral avoidance test (BAT) 52 were risk allele carriers. For sample characteristics and genotype counts see supplementary table 3 .

\section{Paradigms}

Startle reactivity was investigated in three paradigms selected to allow for hierarchical analysis of startle reactivity with increasing complexity, focusing on a) startle habituation during an emotion-potentiated startle paradigm ${ }^{33}$, b) startle potentiation triggered by a threatening environment during the BAT ${ }^{47}$, and c) startle generalization during context-conditioning ${ }^{46}$. For a detailed description on startle methodology, paradigms and statistical analyses see supplementary methods.

\section{Functional assessment: Fear Network}

Sample

Healthy volunteers from two studies (Study 1: $\mathrm{N}=72,{ }^{48}$; Study 2: $\mathrm{N}=38$ ) with identical experimental design during a cue fear conditioning paradigm were included. All participants were right-handed with normal or corrected-to-normal vision. All participants were recruited from the MEGA study wave 2. Participants were grouped into risk and no-risk allele carriers as described above (risk: $\mathrm{N}=33$ ). For sample characteristics see supplementary table 3.

\section{Experimental Design}


Two visual stimuli served as conditioned stimuli (CSs) and three electro-tactile stimuli as US. The CS+ was always, and the CS- never was followed by the US while skin conductance responses (SCRs), fear ratings and fMRI data, were acquired (see ${ }^{48,49}$ ).

All behavioral data (SCR, ratings) were analyzed using SPSS 22 for Windows (IBM Corp., Armonk, New York) using repeated measures analyses for CS type per experimental phase (first half acquisition, second half acquisition, extinction). Rating values after fear acquisition were corrected for pre-acquisition scores. An $\alpha$-level of $p<.05$ was considered significant (unless otherwise stated), and Greenhouse-Geisser corrected degrees of freedom were used when appropriate. For a detailed description on fMRI data acquisition, preprocessing and statistical analyses see supplementary methods.

\section{Agoraphobic behavior in heterozygous Glrb knockout mice}

\section{Animals}

The spastic mouse ${ }^{50,51}$ has an insertion of a LINE1 element into intron 5, resulting in lower expression levels of the full-length glycine receptor beta $\left(G / r b^{s p a}\right)$. Heterozygous GIrb ${ }^{+/ s p a}$ do not show the spastic phenotype. All experiments were done with adult C57BL/6J and C57BL/6J Glrb ${ }^{+/ s p a}$ mice (Jackson Laboratories, Bar Harbor, ME, US) in accordance with European Union guidelines, as approved by our institutional animal care and utilization committee. The experiments were authorized under reference number 55.2-2531.01-95/13. For details on genotyping, membrane preparation, mRNA quantification, Western Blot and immunostaining see supplementary methods.

\section{Open field test}

Wild-type and heterozygous $G / r b^{+/ s p a}$ mice were tested individually for anxiety like behaviour. They were placed in a $48 \times 48 \mathrm{~cm}$ square box, illuminated with $\sim 40$ lux. Animals were monitored for 10 or 30 min each and tracked with the Video Mot Software (TSE, Germany). For analysis, the box was divided into fields of interest: centre of the arena $(24 \times 24 \mathrm{~cm})$ versus the periphery. The first $5 \mathrm{~min}$ were analysed counting entries and time spent in centre ${ }^{52}$. Differences between genotypes were tested using a two-way ANOVA with Bonferroni posttest or an unpaired t-test. 


\section{Results}

\section{GLRB locus, agoraphobic cognitions and PD/AG}

After quality control of post-imputational data, altogether 1,370 healthy volunteers from MEGA wave 1 with information of 7,071,105 autosomal markers were available for analysis. GWAS analysis on ACQ yielded 122 markers with $p<1 \times 10^{-5}$ (figure 1 a, supplementary table 4) distributed over 22 genomic regions (supplementary table 5). On chromosome 4, genome-wide significance was reached for the imputed SNPs rs78726293 $\left(p=3.3 \times 10^{-8} ; I Q S=0.58\right)$ and $r s 191260602\left(p=3.9 \times 10^{-8} ; I Q S=0.68\right)$, both located in an intronic region of the glycine receptor beta $(G L R B)$ gene. This locus was supported by a nearly genome-wide signal, rs115177500 $\left(p=8.3 \times 10^{-8}\right)$, upstream of $G L R B$, and by further 26 strongly associated variants $\left(p<1 \times 10^{-4}\right)$ within a window of $400 \mathrm{~Kb}$ around this gene (figure 1b).

Both genome-wide significant polymorphisms rs78726293 and rs191260602 and further 18 SNPs fully tagging GLRB were genotyped and analyzed in a larger ACQ sample (MEGA waves 1 and 2; $\mathrm{N}=2,547$; table 1). The genome-wide significant SNPs, rs78726293 and rs191260602, and in addition rs17035816 were strongly associated in the larger sample $\left(p_{\text {rs } 78726293}=4.3 \times 10^{-4} ; p_{\text {rs } 191260602}=8.8 \times 10^{-5} ; p_{\text {rs } 17035816}=3.8 \times 10^{-4}\right)$, always with the minor allele increasing ACQ sum scores (table 1).

All 20 examined SNPs were additionally analyzed for association with a SCL-90 based dichotomous agoraphobia phenotype in the Nijmegen Biomedical Study (NBS) comprising 3,845 healthy participants. The minor allele of a further SNP rs7688285, was strongly associated with increased risk for the SCL-90 based dichotomous agoraphobia phenotype $\left(p_{\text {rs } 7688285}=4.3 \times 10^{-4} ;\right.$ table 1$)$.

Analysis of the 20 examined SNPs for the categorical phenotype of PD/AG showed an overlap of significant results with both the dimensional ACQ and the dichotomous SCL-90 based agoraphobia phenotype for both genome-wide significant SNPs rs78726293 $\left(p_{\text {rs78726293 }}=0.033\right)$ and $\mathrm{rs} 191260602\left(p_{\text {rs191260602 }}=0.033\right)$, as well as for $r 57688285\left(p=7.6 \times 10^{-5}\right)$. Again, always the minor alleles conveyed genetic risk (table 1).

\section{Functional assessment: Bioinformatic, post mortem and cell system expression analyses}


None of the four strongly associated SNPs could be classified as an expression quantitative trait locus (eQTL) in the GTEx database.

Genotype-specific differences of the promoter region risk variant rs7688285on mRNA expression levels were found in the midbrain ( $N=50 ; A A=0 / A G=12 / G G=38)$, where the minor, risk (A)-allele increased the mean expression of $G L R B$ (beta $=0.498 ; p=0.013$ ) significantly (supplementary figure $2 A$ ). Neither in forebrain ( $N=59 ; A A=1 / A G=16 / G G=42 ; p=0.421$ ) nor in the amygdalae $(\mathrm{N}=56 ; \mathrm{AA}=2 / \mathrm{AG}=14 / \mathrm{GG}=40 ; p=0.487)$, rs7688285 affected mRNA expression.

In line with data of human tissue, normalized luciferase activity was significantly increased for the (A)-allele of rs7688285 compared to the (G)-allele $(0.185 \pm 0.09$ vs. $0.155 \pm 0.09, p=0.029, \mathrm{~N}=7$; supplementary figure $2 \mathrm{~B}$ ).

\section{Functional assessment: Startle Reflex}

Startle habituation (figure 2A) during an emotion-potentiated startle paradigm was significant in a healthy sample of no-risk allele carriers $(N=77 ; t(76)=5.12, p<0.004)$, but not in risk allele carriers $(\mathrm{N}=24 ; t(23)=1.15, p>0.60)$ indicating impaired startle habituation in risk allele carriers (figure $2 \mathrm{~A}$ ).

During a Behavioral Avoidance Test (figure 2B), PD/AG patients carrying a GLRB risk allele $(\mathrm{N}=52)$ exhibit increased startle responsivity during threat as reflected in stronger increases in startle potentiation from last minute of anticipation to first minute of exposure than no-risk allele carriers $\left(N=63\right.$; Group $x$ Time $\left.F(1,113)=5.22, p<0.05 ; \eta^{2}=0.044\right)$.

In a context conditioning paradigm (figure $2 \mathrm{C}$ ) healthy risk-allele carriers $(\mathrm{N}=23$ ) exhibited as well overall stronger startle potentiation during acquisition compared to no-risk allele carriers $\left(\mathrm{N}=63 ; F(1,74)=4.39, p=0.040, \eta_{\mathrm{p}}^{2}=0.056\right)$. The high risk group revealed potentiated startle in both the threat (CTX+) and the safety context (CTX-) without difference between the two $(t(22)=0.11, p=0.915)$, in contrast to the no-risk group that featured potentiated startle in the CTX+ only $(t(52)=2.75, p=0.008)$. Accordingly, startle potentiation in the CTX- was significantly higher for risk-allele carriers compared to the no-risk group $(t(74)=2.50, p=0.015)$. Again pointing to impaired startle habituation, we found that startle responses in CTX- declined across acquisition in the no-risk group (Acquisition1 vs. Acquisition2: $t(52)=2.79, p=0.007)$, but not in the risk group $(t(22)=0.24, p=0.811)$. Finally, we observed no group differences during extinction, but the high risk group showed a stronger 
sensitization of startle magnitudes in CTX+ during test, i.e. spontaneous recovery (Context $\mathrm{x}$ Group interaction: $\left.F(1,74)=5.77, p=.019, \eta_{p}^{2}=0.072\right)$. The resulting significantly increased startle responses in CTX+ in the risk compared to the no-risk group $(t(74)=2.78, p=0.007)$ further emphasizes increased responsivity of the startle system in the risk group.

\section{Functional assessment: Fear Network}

During late cue conditioning, GLRB risk-allele carriers showed significantly stronger CS+-reactivity in several regions of interest of the fear network (thalamus, putamen/pallidum at $\mathrm{p}_{\text {(FEW-corrected) }}$; figure $3 \mathrm{~A}, \mathrm{~B}$ and supplementary table 6 ) as well as stronger CS+-reactivity in skin conductance responses (SCRs) [stimulus $\mathrm{x}$ group interaction: $F(1,105)=3.56$, one-sided $p=0.031, \eta^{2}=0.03$, figure $\left.3 F\right]$.

In addition, GLRB risk-allele carriers showed significantly stronger general CSunspecific activation in left pre- and post-central gyrus (figure 3D), the bilateral pallidum (figure $3 \mathrm{E}$ ) and putamen as well as the right thalamus during both early and late acquisition in absence of any main effects of group on SCRs $\left[F(1,105)=3.56, p=0.17, \eta^{2}=0.02\right]$. In addition, during early acquisition GLRB risk carriers also displayed generally stronger activation in the left amygdala (figure $3 \mathrm{C}$ ) than no-risk allele carriers as well as stronger bilateral insula activation during late acquisition (supplementary table 6).

\section{Agoraphobic behavior in heterozygous Glrb Knockout mice}

In heterozygous Glrb ${ }^{+/ s p a}$ mice, decreased GIrb expression levels were observed both at the mRNA and protein level, in particular in thalamus and hippocampus (supplementary figure 3). Interestingly, these regions were found to be differentially activated as a function of GLRB genotype in the human fear conditioning paradigm (see above). Heterozygous GIrb ${ }^{+/ s p a}$ mice showed a significantly enhanced agoraphobic behavior demonstrated by less time spent in the center of the open field $(+/+0.52 \pm 0.05 \mathrm{~min} ;+/$ spa $0.4 \pm 0.03 \mathrm{~min})$. Both groups of animals, however, did not differ in distance traveled and number of entries into the field (figure 4). 


\section{Discussion}

Beyond classical diagnostic phenotypes, the specification of functional dimensions of behavior as done in the Research Domain Criteria (RDoC) approach ${ }^{53}$ aims at obtaining insights into the biological basis of mental illness. In this context, negative valence and arousal systems ${ }^{54}$ are relevant to PD/AG. The development of PD/AG in early adulthood is preceded by increased scores on dimensional anxiety phenotypes with negative valence such as anxiety sensitivity ${ }^{55}$ and agoraphobic cognitions ${ }^{56}$ which are thus relevant proxies for PD/AG.

To start with, we therefore performed a hypothesis-generating GWAS using the ACQ in a German cohort (MEGA wave 1) which suggested that allelic variation in GLRB on chromosome 4q31-34 is associated with quantitative ACQ scores. Results from a larger sample (MEGA waves 1 and 2) and two independent sample (NBS, PanicNet waves 1 and 2) supported this finding and extended it to a dichotomous agoraphobia phenotype as well as the categorical phenotype PD/AG. This chromosomal locus (4q31-34) had previously been proposed as genome-wide linkage locus for anxiety disorders ${ }^{57}$. In the linkage scan, the most significant marker (D4S413) is located a mere $384 \mathrm{~kb}$ from rs7688285 in GLRB. On the molecular level, we found the risk allele to go along with altered GLRB expression in vitro and post mortem.

In the next step we asked which neural mechanisms are linked to the behavioral phenotypes, along the RDoC idea. The inhibitory glycine system is more ancient than the GABA system and thus more prevalent in evolutionary older brain regions from the spinal cord to the midbrain ${ }^{58}$. The effects of glycine are mediated by heteromeric receptors formed by Glyalpha $1-4$ and Gly beta subunits ${ }^{59}$. Single point mutations in the GLRB gene have recently been shown to lead to hyperekplexia 2 (OMIN \#614619), a rare neurological disorder with Mendelian heritability ${ }^{60,61}$. These patients suffer from exaggerated startle responses to unexpected noise or tactile stimuli. On the translational level, the phenotype is confirmed by the spastic mouse (featuring a substantial reduction of Glrb), which is characterized by an increased startle reaction ${ }^{62}$. While, in humans, startle symptoms may diminish with age, (agora-) phobic behavior may become a more prominent clinical feature 63,64 . 
Based on the startle phenotype of hyperekplectic patients and the observation that startle reactivity is inherited ${ }^{65,66}$, we investigated functional intermediate phenotypes with a focus on startle response as possible immediate functional consequences of GLRB genetic variation. Three different samples provide converging evidence that GLRB risk SNPs result in slower habituation, stronger potentiation and generalization of startle, although subtler as compared to the - potentially more deleterious -mutations in GLRB causing hyperekplexia. These genetic modulations of defensive reactivity of brain stem reflexes during potential threat, which is mediated at a subcortical level ${ }^{56,67}$, did not go along with concordant panic or anxiety ratings. Accordingly, at the level of brain function - and possibly mediated by GLRB expression changes in midbrain as suggested by our post-mortem data - GLRB risk alleles were associated not only with increased activation of the fear network, but with a generally stronger activation of sensory networks including the thalamus and postcentral gyrus as well as the motor network (precentral gyrus, pallidum and putamen) suggesting a general higher reactivity independent of the presence of an aversive stimulus.

Being a very basic mechanism, the observed increased startle responses likely suggest a link between the Arousal system and the Negative valence system causing an increased likelihood to shy away from threats, i.e. increased defensive reactivity 53,54 . Consistent with our findings in humans and extending the known phenotype of the spastic mouse, we showed that partial Glrb knock-out mice exhibited avoidance of a novel open space, a behavior we recently confirmed to be related to agoraphobic fear in humans ${ }^{3}$. At the mechanistic level, it is somewhat puzzling that the phenotype-associated rs7688285 A allele in fact was not found with decreased, but instead increased GLRB expression in a heterologous cell system as well as in post mortem samples. However, an increase in GLRB expression does not necessarily result in enhanced functional pentameric glycine receptors, which are composed of both GlyRbeta and GlyRalpha subunits. An enhanced expression of GlyRbeta might e.g. result in an upregulation of the 2alpha/3beta variant, to the disadvantage of the functionally different homomeric GlyR alpha receptor ${ }^{68}$, and hence at the functional level may well have similar consequences as the mouse knockout phenotype. As the subunit composition of the glycine receptor changes during the life span ${ }^{69,70}$, this may be particularly relevant during neural development. As such divergences between mouse knockout and human genetic variants are a common though not well understood 
phenomenon in psychiatric genetics (e.g. for the 5HTT and NPSR1 genes), mouse models for specific human genetic variants, in our case of $G R L B$, are definitively needed.

There are a few limitations of our study. First, this is a study in rather homogenous proband and patient samples from Germany and the neighboring Netherlands. Thus, the generalizability to other populations remains to be elucidated. Second, the sample sizes are comparably small, especially for the PD/AG sample. Hence, further replication studies and metaanalyses ${ }^{30}$ e.g. in the context of a psychiatric genomics consortium framework are paramount. Third, the associated polymorphisms differed between samples. This may, however simply be due to the different phenotypes studied with greater power of the dimensional sample for rare polymorphisms with bigger effect sizes and greater power of the dichotomous sample for the more common polymorphisms. Nevertheless, the ultimate phenotype PD/AG demonstrated significant associations for both types of polymorphisms. Fourth, the human intermediate phenotype paradigms were not specifically designed to examine GLRB gene effects on startle responses. The proximity of the startle reaction to the hyperekplexia phenotype in our opinion, however, is close enough to overcome this shortcoming. Fifth, the definition of the risk population in the intermediate phenotype paradigms is based on a combination of significant alleles, as sample sizes precluded genebased analyses as well as investigating the effects of individual rare variants on their own. Reverse-phenotyping studies which are designed to specifically test a potential influence of specific GLRB variants on intermediate phenotypes in larger samples are needed. Deep sequencing of the GLRB gene for rare variants in larger samples of patients as compared to healthy probands with calculation of a polyallelic risk score will help to clarify this issue ${ }^{71}$.

In summary, our findings provide evidence that $G L R B$ allelic variation may contribute not only to the rare severe neurological disorder hyperekplexia, but also to the risk of the comparably milder categorical anxiety disorder PD/AG by increasing startle response and, as a result, agoraphobic cognitions. Our data point to the startle reflex being one pathomechanism in PD/AG. Within the RDoC matrix, this places GLRB in the Arousal gene list, while adding PD/AG to the clinical entities linked to this domain. As GLRB can be subjected to pharmacological interventions, its modulation may comprise a novel therapeutic option in PD/AG. 


\section{References}

1. Wittchen HU, Jacobi F, Rehm J, Gustavsson A, Svensson M, Jonsson B et al. The size and burden of mental disorders and other disorders of the brain in Europe 2010. European neuropsychopharmacology : the journal of the European College of Neuropsychopharmacology 2011; 21(9): 655-679.

2. Hofmann SG, Alpers GW, Pauli P. Phenomenology of Panic and Phobic Disorders. Oxford University Press: New York, 2008.

3. Walz N, Mühlberger A, Pauli P. A human open field test reveals thigmotaxis related to agoraphobic fear. Biological psychiatry 2016.

4. Pauli P, Amrhein C, Muhlberger A, Dengler W, Wiedemann G. Electrocortical evidence for an early abnormal processing of panic-related words in panic disorder patients. International journal of psychophysiology : official journal of the International Organization of Psychophysiology 2005; 57(1): 33-41.

5. Chambless DL, Caputo GC, Bright P, Gallagher R. Assessment of fear of fear in agoraphobics: the body sensations questionnaire and the agoraphobic cognitions questionnaire. J Consult Clin Psychol 1984; 52(6): 1090-1097.

6. Fyer AJ, Mannuzza S, Chapman TF, Martin LY, Klein DF. Specificity in familial aggregation of phobic disorders. Archives of general psychiatry 1995; 52(7): 564-573.

7. Noyes R, Jr., Crowe RR, Harris EL, Hamra BJ, McChesney CM, Chaudhry DR. Relationship between panic disorder and agoraphobia. A family study. Archives of general psychiatry 1986; 43(3): 227-232.

8. Mosing MA, Gordon SD, Medland SE, Statham DJ, Nelson EC, Heath AC et al. Genetic and environmental influences on the co-morbidity between depression, panic disorder, agoraphobia, and social phobia: a twin study. Depression and anxiety 2009; 26(11): 1004-1011.

9. Gottschalk MG, Domschke K. Novel developments in genetic and epigenetic mechanisms of anxiety. Current opinion in psychiatry 2016; 29(1): 32-38.

10. Hamilton SP. Linkage and association studies of anxiety disorders. Depression and anxiety 2009; 26(11): 976-983. 
11. Howe AS, Buttenschon HN, Bani-Fatemi A, Maron E, Otowa T, Erhardt A et al. Candidate genes in panic disorder: meta-analyses of 23 common variants in major anxiogenic pathways. Molecular psychiatry 2015.

12. Maron E, Hettema JM, Shlik J. Advances in molecular genetics of panic disorder. Molecular psychiatry 2010; 15(7): 681-701.

13. Domschke K, Freitag CM, Kuhlenbaumer G, Schirmacher A, Sand P, Nyhuis $P$ et al. Association of the functional V158M catechol-O-methyl-transferase polymorphism with panic disorder in women. The international journal of neuropsychopharmacology / official scientific journal of the Collegium Internationale Neuropsychopharmacologicum 2004; 7(2): 183-188.

14. Hamilton SP, Slager SL, Heiman GA, Deng Z, Haghighi F, Klein DF et al. Evidence for a susceptibility locus for panic disorder near the catechol-O-methyltransferase gene on chromosome 22. Biological psychiatry 2002; 51(7): 591-601.

15. Rothe C, Koszycki D, Bradwejn J, King N, Deluca V, Tharmalingam S et al. Association of the Val158Met catechol O-methyltransferase genetic polymorphism with panic disorder. Neuropsychopharmacology : official publication of the American College of Neuropsychopharmacology 2006; 31(10): 2237-2242.

16. Domschke K, Reif A, Weber H, Richter J, Hohoff C, Ohrmann P et al. Neuropeptide S receptor gene -- converging evidence for a role in panic disorder. Molecular psychiatry 2010; 16(9): 938-948.

17. Deckert J, Catalano M, Syagailo YV, Bosi M, Okladnova O, Di Bella D et al. Excess of high activity monoamine oxidase $A$ gene promoter alleles in female patients with panic disorder. Human molecular genetics 1999; 8(4): 621-624.

18. Domschke K, Tidow N, Kuithan H, Schwarte K, Klauke B, Ambree $\mathrm{O}$ et al. Monoamine oxidase A gene DNA hypomethylation - a risk factor for panic disorder? The international journal of neuropsychopharmacology / official scientific journal of the Collegium Internationale Neuropsychopharmacologicum 2012; 15(9): 1217-1228.

19. Reif A, Richter J, Straube B, Hofler M, Lueken U, Gloster AT et al. MAOA and mechanisms of panic disorder revisited: from bench to molecular psychotherapy. Molecular psychiatry 2014; 19(1): 122-128.

20. Domschke K, Deckert J, O'Donovan M C, Glatt SJ. Meta-analysis of COMT val158met in panic disorder: ethnic heterogeneity and gender specificity. American journal of 
medical genetics Part $B$, Neuropsychiatric genetics : the official publication of the International Society of Psychiatric Genetics 2007; 144B(5): 667-673.

21. Reif A, Weber H, Domschke K, Klauke B, Baumann C, Jacob CP et al. Meta-analysis argues for a female-specific role of MAOA-uVNTR in panic disorder in four European populations. American journal of medical genetics Part B, Neuropsychiatric genetics : the official publication of the International Society of Psychiatric Genetics 2012; 159B(7): 786-793.

22. Erhardt A, Czibere L, Roeske D, Lucae S, Unschuld PG, Ripke S et al. TMEM132D, a new candidate for anxiety phenotypes: evidence from human and mouse studies. Molecular psychiatry 2011; 16(6): 647-663.

23. Otowa T, Kawamura Y, Nishida N, Sugaya N, Koike A, Yoshida E et al. Meta-analysis of genome-wide association studies for panic disorder in the Japanese population. Translational psychiatry 2012; 2: e186.

24. Otowa T, Yoshida E, Sugaya N, Yasuda S, Nishimura Y, Inoue K et al. Genome-wide association study of panic disorder in the Japanese population. Journal of human genetics 2009; 54(2): 122-126.

25. Erhardt A, Akula N, Schumacher J, Czamara D, Karbalai N, Muller-Myhsok B et al. Replication and meta-analysis of TMEM132D gene variants in panic disorder. Translational psychiatry 2012; 2: e156.

26. Schizophrenia Working Group of the Psychiatric Genomics C. Biological insights from 108 schizophrenia-associated genetic loci. Nature 2014; 511(7510): 421-427.

27. Fullerton JM, Willis-Owen SA, Yalcin B, Shifman S, Copley RR, Miller SR et al. Humanmouse quantitative trait locus concordance and the dissection of a human neuroticism locus. Biological psychiatry 2008; 63(9): 874-883.

28. Shifman S, Bhomra A, Smiley S, Wray NR, James MR, Martin NG et al. A whole genome association study of neuroticism using DNA pooling. Molecular psychiatry 2008; 13(3): 302-312.

29. Walter S, Glymour MM, Koenen K, Liang L, Tchetgen Tchetgen EJ, Cornelis M et al. Performance of polygenic scores for predicting phobic anxiety. PloS one 2013; 8(11): e80326. 
30. Otowa T, Hek K, Lee M, Byrne EM, Mirza SS, Nivard MG et al. Meta-analysis of genome-wide association studies of anxiety disorders. Molecular psychiatry 2016.

31. Otowa T, Maher BS, Aggen SH, McClay JL, van den Oord EJ, Hettema JM. Genomewide and gene-based association studies of anxiety disorders in European and African American samples. PloS one 2014; 9(11): e112559.

32. Ehlers A, Margraf J. Fragebogen zu körperbezogenen Ängsten, Kognitionen und Vermeidung (AKV). Beltz Test 2001; Göttingen.

33. Domschke K, Gajewska A, Winter B, Herrmann MJ, Warrings B, Muhlberger A et al. ADORA2A Gene variation, caffeine, and emotional processing: a multi-level interaction on startle reflex. Neuropsychopharmacology : official publication of the American College of Neuropsychopharmacology 2012; 37(3): 759-769.

34. Schiele MA, Ziegler C, Holitschke K, Schartner C, Schmidt B, Weber H et al. Influence of 5-HTT variation, childhood trauma and self-efficacy on anxiety traits: a geneenvironment-coping interaction study. Journal of neural transmission 2016; 123(8): 895-904.

35. Hoogendoorn EH, Hermus AR, de Vegt F, Ross HA, Verbeek AL, Kiemeney LA et al. Thyroid function and prevalence of anti-thyroperoxidase antibodies in a population with borderline sufficient iodine intake: influences of age and sex. Clinical chemistry 2006; 52(1): 104-111.

36. Derogatis LR, Cleary PA. Factorial invariance across gender for the primary symptom dimensions of the SCL-90. The British journal of social and clinical psychology 1977; 16(4): 347-356.

37. Derogatis LR, Lipman RS, Covi L. SCL-90: an outpatient psychiatric rating scale-preliminary report. Psychopharmacology bulletin 1973; 9(1): 13-28.

38. Arrindell WA, Ettema JHM. SCL-90, Handleiding bij een multidimensionele psychopathologie indicator. Swets \& Zeitlinger: Lisse, 1986.

39. Gloster AT, Wittchen HU, Einsle F, Hofler M, Lang T, Helbig-Lang S et al. Mechanism of action in CBT (MAC): methods of a multi-center randomized controlled trial in 369 patients with panic disorder and agoraphobia. Eur Arch Psychiatry Clin Neurosci 2009; 259 Suppl 2: S155-166. 
40. Weber H, Richter J, Straube B, Lueken U, Domschke K, Schartner C et al. Allelic variation in CRHR1 predisposes to panic disorder: evidence for biased fear processing. Molecular psychiatry 2015.

41. Rietschel $M$, Mattheisen $M$, Degenhardt $F$, Genetic $R$, Outcome in $P$, Muhleisen TW et al. Association between genetic variation in a region on chromosome 11 and schizophrenia in large samples from Europe. Molecular psychiatry 2012; 17(9): 906917.

42. Fuchsberger $C$, Abecasis GR, Hinds DA. minimac2: faster genotype imputation. Bioinformatics 2015; 31(5): 782-784.

43. Li Y, Willer CJ, Ding J, Scheet P, Abecasis GR. MaCH: using sequence and genotype data to estimate haplotypes and unobserved genotypes. Genetic epidemiology 2010; 34(8): 816-834.

44. Genomes Project C, Auton A, Brooks LD, Durbin RM, Garrison EP, Kang HM et al. A global reference for human genetic variation. Nature 2015; 526(7571): 68-74.

45. Weber H, Klamer D, Freudenberg F, Kittel-Schneider S, Rivero O, Scholz CJ et al. The genetic contribution of the NO system at the glutamatergic post-synapse to schizophrenia: Further evidence and meta-analysis. European neuropsychopharmacology : the journal of the European College of Neuropsychopharmacology 2013; 24(1): 65-85.

46. Glotzbach-Schoon E, Andreatta M, Reif A, Ewald H, Troger C, Baumann C et al. Contextual fear conditioning in virtual reality is affected by 5HTTLPR and NPSR1 polymorphisms: effects on fear-potentiated startle. Frontiers in behavioral neuroscience 2013; 7: 31.

47. Richter J, Hamm AO, Pane-Farre CA, Gerlach AL, Gloster AT, Wittchen HU et al. Dynamics of defensive reactivity in patients with panic disorder and agoraphobia: implications for the etiology of panic disorder. Biological psychiatry 2012; 72(6): 512520.

48. Scharfenort R, Lonsdorf TB. Neural correlates of and processes underlying generalized and differential return of fear. Social cognitive and affective neuroscience 2015.

49. Boucsein W, Fowles DC, Grimnes S, Ben-Shakhar G, roth WT, Dawson ME et al. Publication recommendations for electrodermal measurements. Psychophysiology 2012; 49(8): 1017-1034. 
50. Becker K, Braune M, Benderska N, Buratti E, Baralle F, Villmann C et al. A retroelement modifies pre-mRNA splicing: the murine Glrb(spa) allele is a splicing signal polymorphism amplified by long interspersed nuclear element insertion. The Journal of biological chemistry 2012; 287(37): 31185-31194.

51. Kingsmore SF, Giros B, Suh D, Bieniarz M, Caron MG, Seldin MF. Glycine receptor beta-subunit gene mutation in spastic mouse associated with LINE-1 element insertion. Nature genetics 1994; 7(2): 136-141.

52. Crawley JN, Paylor R. A proposed test battery and constellations of specific behavioral paradigms to investigate the behavioral phenotypes of transgenic and knockout mice. Hormones and behavior 1997; 31(3): 197-211.

53. Cuthbert BN, Insel TR. Toward the future of psychiatric diagnosis: the seven pillars of RDoC. BMC medicine 2013; 11: 126.

54. Hamm AO, Richter J, Pane-Farre C, Westphal D, Wittchen HU, Vossbeck-Elsebusch AN et al. Panic disorder with agoraphobia from a behavioral neuroscience perspective: Applying the research principles formulated by the Research Domain Criteria (RDoC) initiative. Psychophysiology 2016; 53(3): 312-322.

55. McNally RJ. Anxiety sensitivity and panic disorder. Biological psychiatry 2002; 52(10): 938-946.

56. Godemann F, Schabowska A, Naetebusch B, Heinz A, Strohle A. The impact of cognitions on the development of panic and somatoform disorders: a prospective study in patients with vestibular neuritis. Psychological medicine 2006; 36(1): 99-108.

57. Kaabi B, Gelernter J, Woods SW, Goddard A, Page GP, Elston RC. Genome scan for loci predisposing to anxiety disorders using a novel multivariate approach: strong evidence for a chromosome 4 risk locus. American journal of human genetics 2006; 78(4): 543-553.

58. Lynch JW. Molecular structure and function of the glycine receptor chloride channel. Physiological reviews 2004; 84(4): 1051-1095.

59. Schaefer N, Langlhofer G, Kluck CJ, Villmann C. Glycine receptor mouse mutants: model systems for human hyperekplexia. British journal of pharmacology 2013; 170(5): 933-952. 
60. Chung SK, Bode A, Cushion TD, Thomas RH, Hunt C, Wood SE et al. GLRB is the third major gene of effect in hyperekplexia. Human molecular genetics 2013; 22(5): 927940.

61. James VM, Bode A, Chung SK, Gill JL, Nielsen M, Cowan FM et al. Novel missense mutations in the glycine receptor beta subunit gene (GLRB) in startle disease. Neurobiology of disease 2013; 52: 137-149.

62. Becker CM. Disorders of the inhibitory glycine receptor: the spastic mouse. FASEB journal : official publication of the Federation of American Societies for Experimental Biology 1990; 4(10): 2767-2774.

63. Al-Owain M, Colak D, Al-Bakheet A, Al-Hashmi N, Shuaib T, Al-Hemidan A et al. Novel mutation in GLRB in a large family with hereditary hyperekplexia. Clinical genetics 2012; 81(5): 479-484.

64. Tijssen MAJ, Rees MI. Hyperekplexia. In: Pagon RA, Adam MP, Ardinger HH, Wallace SE, Amemiya A, Bean LH et al. (eds). GeneReviews(R). University of Washington: Seattle (WA), 2012.

65. Anokhin AP, Golosheykin S, Heath AC. Genetic and environmental influences on emotion-modulated startle reflex: a twin study. Psychophysiology 2007; 44(1): 106112.

66. Vaidyanathan $\mathrm{U}$, Malone SM, Miller MB, McGue M, lacono WG. Heritability and molecular genetic basis of acoustic startle eye blink and affectively modulated startle response: a genome-wide association study. Psychophysiology 2014; 51(12): 12851299.

67. Davis M, Walker DL, Miles L, Grillon C. Phasic vs sustained fear in rats and humans: role of the extended amygdala in fear vs anxiety. Neuropsychopharmacology : official publication of the American College of Neuropsychopharmacology 2010; 35(1): 105135.

68. Li P, Slaughter M. Glycine receptor subunit composition alters the action of GABA antagonists. Visual neuroscience 2007; 24(4): 513-521.

69. Aroeira RI, Ribeiro JA, Sebastiao AM, Valente CA. Age-related changes of glycine receptor at the rat hippocampus: from the embryo to the adult. Journal of neurochemistry 2011; 118(3): 339-353. 
70. Jonsson S, Morud J, Pickering C, Adermark L, Ericson M, Soderpalm B. Changes in glycine receptor subunit expression in forebrain regions of the Wistar rat over development. Brain research 2012; 1446: 12-21.

71. Goldman D, Domschke K. Making sense of deep sequencing. The international journal of neuropsychopharmacology / official scientific journal of the Collegium Internationale Neuropsychopharmacologicum 2014; 17(10): 1717-1725. 


\section{Acknowledgements}

We are grateful to all individuals who participated in this study either as part of the CRC-TRR-58 Mega Study wave 1 and 2 or the German PanicNet wave 1 (multicenter trial "Mechanisms of Action in CBT (MAC)") or wave 2 studies.

The study was supported by the DFG CRC-TRR-58 grants $Z 02$ to JD, AR, MR and PP, $A 08$ to $R B, B 01$ to $A M$ and $P P, B 03$ to $C B, B 06$ to $A R$ and $C B, B 07$ to $T L$, and $C 02$ to $K D$ and JD. RK was supported by the DFG grant KA1623/3-1 and MA by the RTG1253. The MAC study was funded by the German Federal Ministry of Education and Research (BMBF; project no. 01GV0615) as part of the BMBF Psychotherapy Research Funding Initiative. The principal investigators (PIs) of the centers with respective areas of responsibility in the MAC study are: V Arolt (Münster: Overall MAC Program Coordination), HU Wittchen (Dresden: PI for the Randomized Clinical Trial and Manual Development), A Hamm (Greifswald: PI for Psychophysiology), AL Gerlach (Münster: PI for Psychophysiology and Panic subtypes), A Ströhle (Berlin: PI for Experimental Pharmacology), T Kircher (Marburg: PI for functional neuroimaging) and J Deckert (Würzburg: PI for Genetics). Additional site directors in the randomized controlled trial component of the program are as follows: GW Alpers (Würzburg), T Fydrich and L Fehm (Berlin-Adlershof) and T Lang (Bremen). Further support was obtained from the IZKF-Würzburg Z-6 to HW and the IZKF-Würzburg N-258 to LH.

The Nijmegen Biomedical Study is a population-based survey conducted at the Department for Health Evidence and the Department of Laboratory Medicine of the Radboud university medical center. Principal investigators of the Nijmegen Biomedical Study are L.A.L.M. Kiemeney, A.L.M. Verbeek, D.W. Swinkels and B. Franke. The Genome of the Netherlands Project (http://www.bbmriwiki.nl/wiki/Impute2Pipeline), and specifically Freerk van Dijk and Morris Swertz, are thanked for imputation of the genotype data with 1000genomes phase1 integrated version 3 and GoNL4.

We credit the MRC Sudden Death Brain and Tissue Bank, Edinburgh, Scotland for providing brain tissue samples examined in this study. T Töpner, I Reck, N Steigerwald, C Gagel and J Auer are credited for excellent technical assistance. 


\section{Conflict of interest}

Over the last 3 years $V$ Arolt has been a member of the advisory boards and/or gave presentations for the following companies: Astra-Zeneca, Eli Lilly, Janssen-Organon, Lundbeck, Otsuka, Servier, and Trommsdorff. He also received sponsorships for symposia and educational activities from Astra-Zeneca, Jansen-Organon, Lundbeck and Servier. C Büchel received speaker's honoraria from Janssen. $K$ Domschke has received a honorarium for a scientific talk from Hexal. T Kircher received fees for educational programs from Janssen, Eli Lilly, Servier, Lundbeck, Bristol Myers Squibb, Pfizer and Astra-Zeneca. P Pauli and A Mühlberger are shareholders of a commercial company that develops virtual environment research systems for empirical studies in the field of psychology, psychiatry, and psychotherapy. A Ströhle received research funding from Lundbeck, and speaker honoraria from AstraZeneca, Boehringer Ingelheim, Bristol-Myers Squibb, Eli Lilly \& Co, Lundbeck, Pfizer, Wyeth and UCB. He was a consultant for Actelion. Educational grants were given by the Boehringer Ingelheim Fonds, the Eli Lilly International Foundation, JanssenCilag, Pfizer and Eli Lilly \& Co. H-U Wittchen has served as a general consultant (non-product related) for Pfizer, Lundbeck, Organon, Servier and EssexPharma and has received grant funding for his institution from Sanofi Aventis, Pfizer, Lundbeck, Novatis, Essex Pharma, Servier and Wyeth. These cooperations have no relevance to the work that is covered in the manuscript. The other authors declare no conflict of interest.

Supplementary information is available at Molecular Psychiatry's website (http://www.nature.com/mp). Supplementary methods and results, supplementary figures and tables give complimentary information on sample demographics, strategies used for genetic and expression analysis, startle and imaging experiments as well as mouse behavioral analysis. 


\section{Figure legends}

Figure 1: Genome-wide association study (GWAS, $N=1,370$. (A) Manhattan plot: Horizontal lines show threshold for genome-wide significance $\left(p<5 \times 10^{-8}\right.$ in orange) and nominal association ( $p \leq 0.05$ in yellow). (B) Regional plot depicting genome-wide significant GLRB markers on chromosome 4, centered in a genomic region of $2 \mathrm{MB}$. Results are shown as $\log _{10}$ ( $p$-value) for genotyped and imputed SNPs. The SNP showing strongest association is shown in purple. The color of the remaining markers reflects $r^{2}$ of the strongest associated SNP. The recombination rate is plotted in blue.

Figure 2: Startle reflex reactivity (means and standard error as a function of GLRB genotype with a risk genotype, comprising carriers of at least one risk allele of either rs78726293 (A allele), rs7688285 (A allele), rs191260602 (G allele), or rs17035816 (G allele). Depicted are (A) startle habituation during an emotion-potentiated startle paradigm (risk: $\mathrm{N}=24$; no-risk: $\mathrm{N}=77$ ), (B) startle potentiation in PD/AG patients during a behavioral avoidance test (risk: $\mathrm{N}=52$; no-risk: $\mathrm{N}=63$ ), and (C) startle generalization in contextual fear conditioning, its extinction and spontaneous recovery reflected in startle potentiation relative to baseline responses (risk: $\mathrm{N}=23$; no-risk: $\mathrm{N}=53$ ). ${ }^{*} \mathrm{p}<0.05 ;{ }^{* *} \mathrm{p}<0.01{ }^{* * *} \mathrm{p}<0.001$.

Figure 3: Fear Network Activation. Significant group differences at a significance threshold of $\mathrm{pFWE} \mathrm{E}_{\mathrm{SV}}$ between GLRB risk- allele carriers and no-risk allele carriers for CS discrimination in thalamic (A) and striatal regions (B) during the second half of fear acquisition. Group differences during early acquisition (corresponding activation pattern in late acquisition is not shown) in general CS-unspecific neural activation in the amygdala (C) pre-/postcentral areas (D) as well as striatal (putamen) areas (E) and their respective peak-voxel parameter estimates (for illustrative purposes). Corresponding group differences in SCR CSdiscrimination between GLRB non-risk and risk-allele carriers (F). Rc: range-corrected, Errorbars represent s.e.m. Visualization threshold is set to $p<0.01$ for illustrative purposes only.

Figure 4: Agoraphobic behavior in GIrb ${ }^{+/ s p a}$ mice. (A) Open field test of $+/+$ and $+/ s p a$ animals; shown are the first $5 \mathrm{~min}$ of the open field test. Walking pattern of representative $+/+$ and + /spa animals. (B) Time spent in the open center, distance travelled and entries, ${ }^{*} p<0.05$. Note that there are no differences in the distance traveled and in the number of entries between $+/+$ and $+/$ spa mice. Number of animals analyzed were $\mathrm{N}=18$ for $+/$ spa and $\mathrm{N}=13$ for $+/+$ mice. 


\section{Tables}

\section{Table 1: GLRB variants, agoraphobic cognitions and PD/AG}

In the ACQ sample, linear regressions for the dimensional phenotype ACQ were carried out assuming additive risk of the minor allele. Association results for the first and the second validation sample are reported as minor allele frequencies for controls and "cases" (SCL-90 agoraphobia score $\geq 1$, or panic disorder patients, respectively) along with respective association $p$-values. Chromosomal positions correspond to the GRCh38 annotation. Bold indicates nominal $p<0.05$. All $p$-values were rounded to the third decimal.

\begin{tabular}{|c|c|c|c|c|c|c|c|c|c|c|}
\hline \multirow[b]{2}{*}{ SNP_ID } & \multirow[b]{2}{*}{ Chr:Bp } & \multirow{2}{*}{$\begin{array}{c}\text { Allele } \\
\mathrm{m} / \mathrm{M}\end{array}$} & \multicolumn{2}{|c|}{ ACQ Sample (N=2,547) } & \multicolumn{3}{|c|}{ SCL-90 Sample $(\mathrm{N}=3,845)$} & \multicolumn{3}{|c|}{ Case/Control Sample ( $\left.\mathrm{N}=506_{\text {each }}\right)$} \\
\hline & & & Beta & $P$-value & SCL-90 $=0$ & SCL-90 $\geq 1$ & $P$ value & Controls & Cases & $P$-value \\
\hline rs7664666 & 4:157038807 & $T / G$ & 0.01 & 0.602 & 0.032 & 0.040 & 0.140 & 0.065 & 0.057 & 0.567 \\
\hline rs13139693 & 4:157044110 & $\mathrm{T} / \mathrm{C}$ & 0.02 & 0.039 & 0.091 & 0.084 & 0.414 & 0.178 & 0.176 & 0.983 \\
\hline rs7688285 & 4:157047466 & AG & 0.01 & 0.546 & 0.118 & 0.146 & $4.3 \times 10^{-4}$ & 0.225 & 0.344 & $7.6 \times 10^{-5}$ \\
\hline rs2343747 & 4:157047961 & $\mathrm{G} / \mathrm{C}$ & 0.00 & 0.617 & 0.278 & 0.261 & 0.161 & 0.536 & 0.460 & 0.100 \\
\hline rs7689138 & 4:157066577 & $T / G$ & -0.01 & 0.591 & 0.102 & 0.105 & 0.757 & 0.184 & 0.168 & 0.502 \\
\hline rs6812324 & 4:157070440 & $\mathrm{C} / \mathrm{T}$ & 0.01 & 0.452 & 0.197 & 0.189 & 0.494 & 0.391 & 0.338 & 0.201 \\
\hline rs11100093 & 4:157072890 & ATT & 0.01 & 0.530 & 0.156 & 0.145 & 0.269 & 0.296 & 0.265 & 0.322 \\
\hline rs4690879 & 4:157074560 & $\mathrm{C} / \mathrm{T}$ & 0.00 & 0.726 & 0.207 & 0.203 & 0.767 & 0.397 & 0.344 & 0.248 \\
\hline rs78726293 & 4:157079880 & AT & 0.12 & $4.3 \times 10^{-4}$ & 0.019 & 0.012 & 0.052 & 0.016 & 0.038 & 0.033 \\
\hline rs6852066 & 4:157081744 & $\mathrm{T} / \mathrm{C}$ & 0.00 & 0.851 & 0.207 & 0.195 & 0.270 & 0.405 & 0.354 & 0.123 \\
\hline rs2880774 & 4:157106830 & $\mathrm{T} / \mathrm{C}$ & 0.00 & 0.811 & 0.151 & 0.136 & 0.163 & 0.310 & 0.255 & 0.071 \\
\hline rs7655209 & 4:157130233 & AG & 0.01 & 0.361 & 0.172 & 0.172 & 0.936 & 0.281 & 0.320 & 0.242 \\
\hline rs191260602 & 4:157140489 & G/A & 0.13 & $8.8 \times 10^{-5}$ & 0.018 & 0.012 & 0.072 & 0.016 & 0.038 & 0.033 \\
\hline rs17035763 & 4:157145432 & AVG & 0.00 & 0.864 & 0.15 & 0.136 & 0.159 & 0.312 & 0.241 & 0.048 \\
\hline rs7662298 & 4:157166613 & G/A & 0.04 & 0.007 & 0.076 & 0.081 & 0.403 & 0.132 & 0.162 & 0.180 \\
\hline rs17035816 & 4:157167312 & G/A & 0.06 & $3.8 \times 10^{-4}$ & 0.052 & 0.051 & 0.896 & 0.081 & 0.097 & 0.383 \\
\hline rs17035818 & 4:157168560 & $G / C$ & -0.01 & 0.613 & 0.051 & 0.048 & 0.534 & 0.075 & 0.063 & 0.450 \\
\hline rs17035820 & 4:157169837 & T/A & 0.01 & 0.283 & 0.177 & 0.18 & 0.838 & 0.281 & 0.336 & 0.112 \\
\hline rs1129304 & 4:157171270 & ATT & 0.01 & 0.221 & 0.320 & 0.308 & 0.355 & 0.591 & 0.573 & 0.930 \\
\hline rs17035827 & 4:157172585 & $\mathrm{G} / \mathrm{A}$ & 0.02 & 0.055 & 0.102 & 0.101 & 0.954 & 0.162 & 0.213 & 0.047 \\
\hline
\end{tabular}



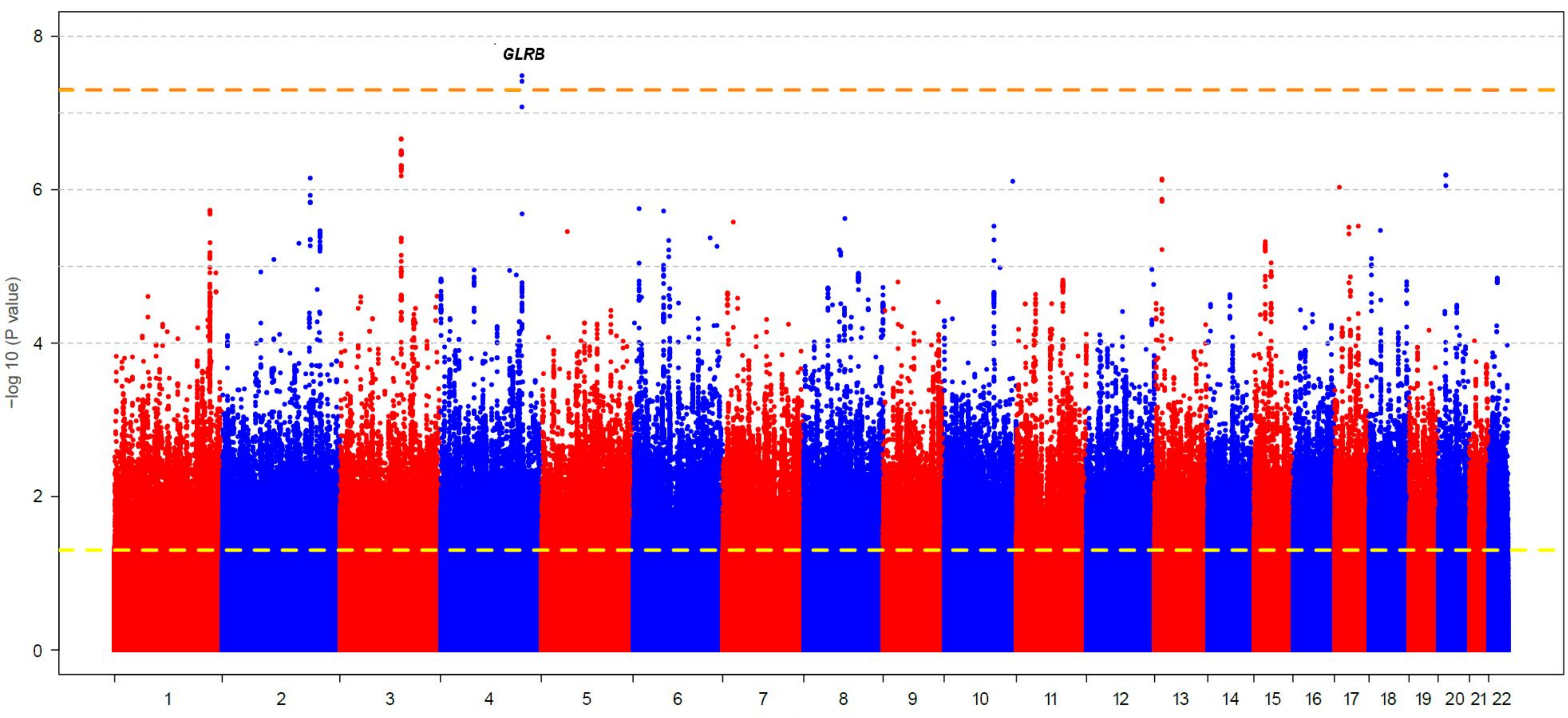

B

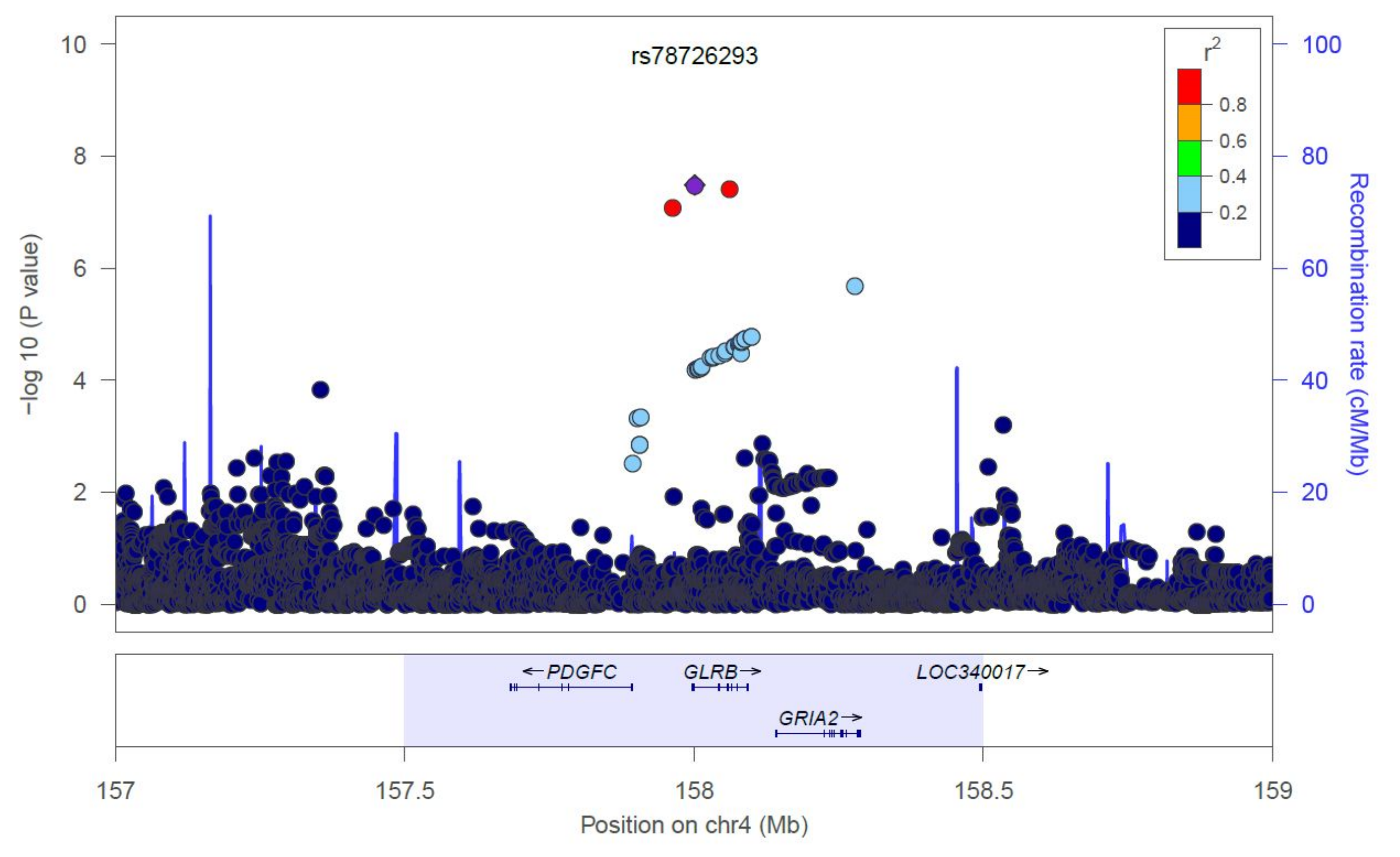



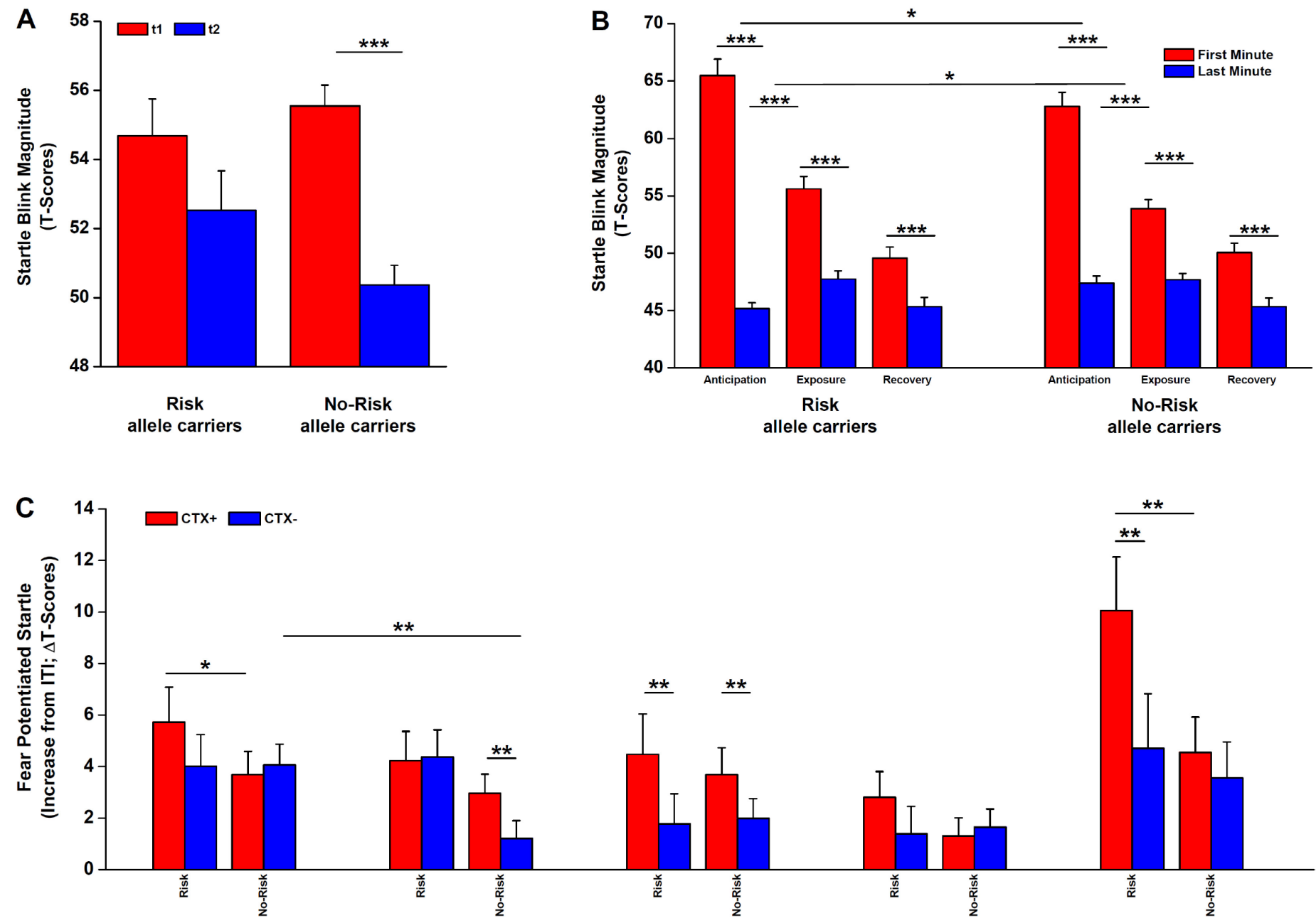

Acquisition 1 


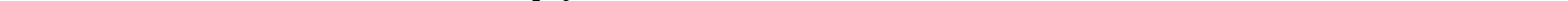



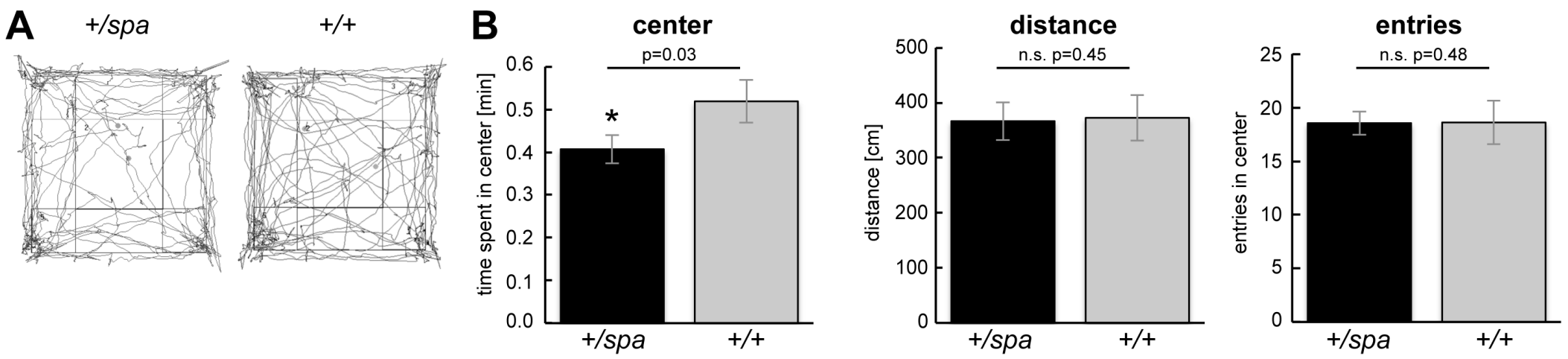


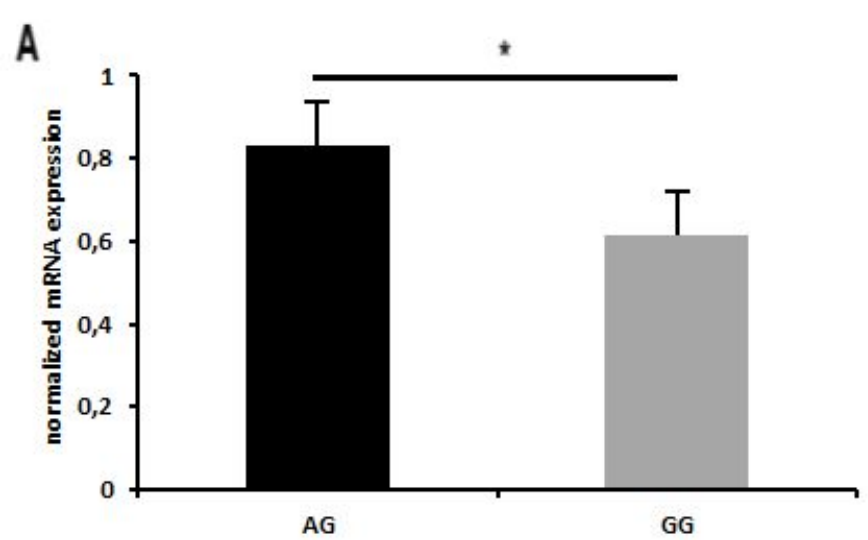

B

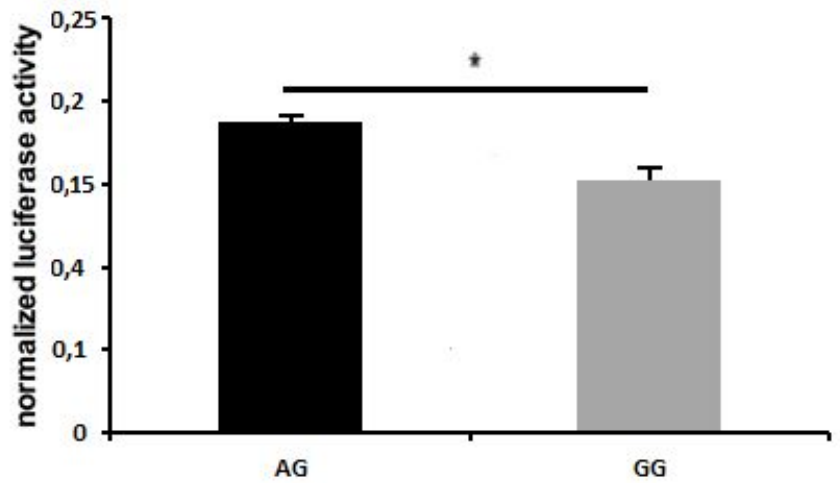


A

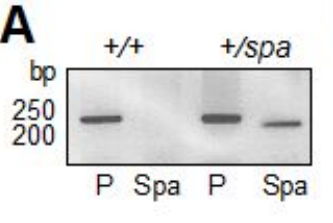

B
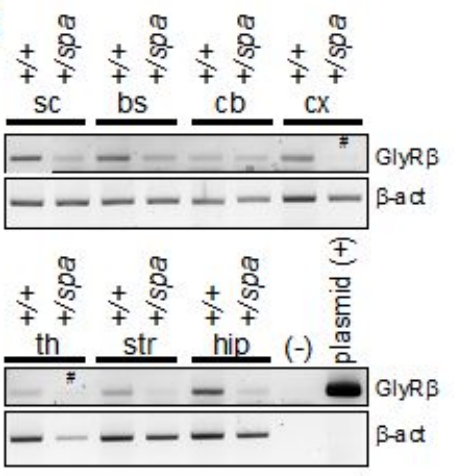

C

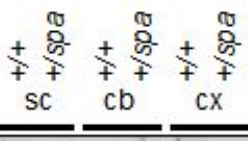

${ }_{93} \overline{\square-1 \text { \& }}$ geph

$58-2: 2$

$42 \Longrightarrow 20$

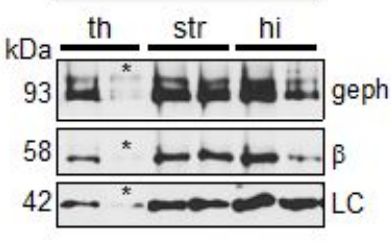

